\title{
Evolution of National University Students' Optical-Science- Technology competition in China
}

Xu Liu, XiangDong Liu, XiaoPing Wang, XiaoDong Zheng, YuanFang Lin, et al.

Xu Liu, XiangDong Liu, XiaoPing Wang, XiaoDong Zheng, YuanFang Lin, Kaiwei Wang, "Evolution of National University Students' Optical-ScienceTechnology competition in China," Proc. SPIE 10452, 14th Conference on Education and Training in Optics and Photonics: ETOP 2017, 104522R (16 August 2017); doi: 10.1117/12.2269748

SPIE Event: 14th Conference on Education and Training in Optics and Photonics, ETOP 2017, 2017, Hangzhou, China 


\title{
Evolution of national university students' Optical-Science-Technology Competition in China
}

\author{
Xu Liu, XiangDong Liu, XiaoPing Wang, XiaoDong Zheng, YuanFang Lin*, Kaiwei Wang \\ College of Optical Science and Engineering, Zhejiang University, Hangzhou 310027, China
}

\begin{abstract}
The goal of National University Students' Optical-Science-Technology Competition (NUSOSTC) is to provide a nation-wide platform for students from the colleges and universities, which have majors in the field of optics and photonics, to communicate and learning each other. Meanwhile, it works on pushing forward the popularity of optoelectronic knowledge, cultivating the students' teamwork and innovation ability, promoting higher education personnel training mode and practice teaching reform, and then improving the quality of talent training. The founding, organizational structure development and overall organizational arrangements of NUSOSTC were introduced in this paper. Besides, the competition logo, theme, title, final date, numbers of participating universities, undertaking universities and cities of the five NUSOSTCs held during 2008 to 2016 and the progress had been made were given in detail.
\end{abstract}

Keywords: Optics Education, Competition game, College student, Undergraduate, Talent training

\section{INTRODUCTION}

Competitions can promote the discipline construction and curriculum reform in colleges and universities, and are helpful to cultivate students' innovative practice ability and teamwork spirit. In the early years, the competitions of college and universities students initiated nation-wide by the Ministry of Education of China (MEC) include the National Undergraduate Electronic Design Contest, the China Undergraduate Mathematical Contest in Modeling, the National College of Mechanical Innovation Design Competition and the National Structure Design Contest for College Students. In July 2008, NUSOSTC platform was created with its website (http://opt.zju.edu.cn/gdjs/) and secretariat were attached to Zhejiang University in the initiative of Professor Xu Liu, the Vice President of the Chinese Optical Society (COS). There are more than 220 colleges and universities have programs or even disciplines in the optics and photonics or optical engineering for undergraduate education, and more than 80 universities provide master degree program for optical engineering. The purpose of organizing NUSOSTC is to take the advantages of optics and photonics disciplines and experts, to provide a training platform for the design, development and integration of optical, mechanical, electrical and computer integrated systems, to create a good environment for the all-round development especially for innovative talents of students, to build a bridge between the national colleges and universities' students majoring in optics and photonics, to promote higher education personnel training mode and practice teaching reform, and constantly improve the quality of personnel training.

*linyuanfang@zju.edu.cn; phone 86571 8795-1681; fax 86571 8795-1681;

14th Conference on Education and Training in Optics and Photonics: ETOP 2017, edited by Xu Liu,

Xi-Cheng Zhang, Proc. of SPIE Vol. 10452, 104522R · C 2017 ICO, IEEE, OSA, SPIE

CCC code: $0277-786 \mathrm{X} / 17 / \$ 18 \cdot$ doi: $10.1117 / 12.2269748$

Proc. of SPIE Vol. 10452 104522R-1 


\section{ORGANIZATIONAL STRUCTURE DEVELOPMENT OF NUSOSTC}

In May 2009, after more than one year of preparatory work, the 1st NUSOSTC final hosted by COS and undertaken by Zhejiang University and China Jiliang University was held in Hangzhou. In July 2009, the Optical Education Division of COS (OEDCOS) was founded. OEDCOS thus became the second and the third NUSOSTC organizer authorized by the COS. In April 2013, MEC issued a notice (http://www.moe.gov.cn/srcsite/A08/s5653/201304/t20130416_150999.html) of the establishment of 2013-2017 ministry of education of the higher education teaching steering committees. Therefore, the National Education Steering Committee of Optics and Photonics (NESCOP) joined as the fourth NUSOSTC co-organizer with OEDCOS which was authorized by the host--COS. In January 2015, on the basis that NUSOSTC had begun to take shape, had a greater impact and the basic conditions of a national competition, OEDCOS and NESCOP applied respectively to their superior management department for listing NUSOSTC since the fifth session as a national competition for colleges and universities students. In March 2015, COS and the 2013-2017 Chinese National Teaching Steering Committee of Electrical Engineering (CNTSCEE) made the following joint announcement after discussion and consultation. According to the requirements of MEC, the fifth and later NUSOSTC would be co-hosted by COS and CNTSCEE so as to attract more colleges and universities' students to participate in the competition and promote the students' practical abilities got through the competition. At the same time, in order to further highlight the professionalism and inheritance of NUSOSTC, COS and CNTSCEE gave OEDCOS and NESCOP carte blanche to cooperate for organizing the competition.

In April 2015, OEDCOS and NESCOP issued an announcement concerning the following NUSOSTC overall organizational arrangements.

$>$ competition name: the national university students' Opt-Sci-Tech Competition (NUSOSTC)

$>$ co-host: COS and CNTSCEE

$>$ co-organizer authorized by the co-host: OEDCOS and NESCOP

$>$ Establish a competition committee of NUSOSTC, which is responsible for the competition management, the collection and choice of the competition title, the operation and maintenance of the competition website and the sustainable development of the competition. The NUSOSTC competition committee consisted of 61 people from optics and photonics related 49 universities, 1 research institutes and 1 enterprise all over the country. In general, discussion is organized by way of email or telephone communication. A secretariat attached to Zhejiang University was set up to deal with daily affairs. The composition change of the NUSOSTC competition committee should be negotiated and notified by the organizer authorized by the competition host.

$>$ In principle, NUSOSTC would be held once every two years, with its final being held in even years. One city and several units should be chosen to undertake each NUSOSTC final. Once there is more than one undertaker, it should be ensured which one is the leading undertaker. In principle, the city undertaking the competition should be the city in which the leading undertaker is located. The undertaker of NUSOSTC final should be decided by the NUSOSTC competition committee in consultation with all the potential undertakers. It may also be decided by voting after the competition committee had examined and verified applications of all the potential undertakers.

$>$ The undertakers of each NUSOSTC final should establish the organizing committee of the corresponding 
competition session, which is responsible for undertaking and implementing the competition. The composition of the competition organizing committee should be announced separately by the secretariat of the competition committee in consultation with the undertakers.

$>$ The secretariat of the competition committee should constitute the NUSOSTC regulations as soon as possible after accumulating many experiences in the actual organization of several competition sessions; report it to the organizer authorized by the competition host so as to release the revised.

$>$ The secretariat of the competition committee should make an official seal of NUSOSTC as soon as possible.

In June 2015, the official seal of NUSOSTC went into service; the competition committee and its secretariat were responsible for the competition specific matters. This indicated that NUSOSTC had become a national platform for colleges and university' students majored in optics and photonics to apply synthetically professional knowledge to innovative practice.

\section{THE PROGRESS OF NUSOSTC}

NUSOSTC is open to undergraduate full-time college students, foreign students and graduates. Team members from different universities, different majors or different disciplines are encouraged. Each team consists of 3 students, including at least 2 undergraduates; each student can only participate in a team. Since 2008, NUSOSTC had been successfully held five sessions. The competition theme, title, final date, numbers of participating universities, undertaking universities and city of the five NUSOSTC finals were given in Table 1.

Table 1. List of previous five NUSOSTC finals

\begin{tabular}{|c|c|c|c|c|c|}
\hline Session & $\begin{array}{l}\text { Competition } \\
\text { theme }\end{array}$ & Competition title & Final date & $\begin{array}{l}\text { Numbers of } \\
\text { participating } \\
\text { universities }\end{array}$ & Undertaking universities/City \\
\hline \multirow{2}{*}{$1 \mathrm{st}$} & \multirow{2}{*}{$\begin{array}{l}\text { light and } \\
\text { energy }\end{array}$} & solar powered vehicle racing & \multirow{2}{*}{$\begin{array}{l}\text { May 29-30, } \\
2009\end{array}$} & \multirow{2}{*}{16} & \multirow{2}{*}{$\begin{array}{l}\text { Zhejiang Univ., China Jiliang } \\
\text { Univ./Hangzhou }\end{array}$} \\
\hline & & solar powered electric light source & & & \\
\hline \multirow[t]{2}{*}{ 2nd } & \multirow[t]{2}{*}{ light and life } & $\begin{array}{l}\text { solar powered vehicle based on } \\
\text { photoelectric navigation }\end{array}$ & \multirow{2}{*}{$\begin{array}{l}\text { August 6-9, } \\
2010\end{array}$} & \multirow[t]{2}{*}{70} & \multirow{2}{*}{$\begin{array}{l}\text { Changchun Univ. of Science and } \\
\text { Technology, Preparatory Office of } \\
\text { China Optical Science and } \\
\text { Technology Museum / Changchun }\end{array}$} \\
\hline & & photoelectric intelligent guide device & & & \\
\hline \multirow{2}{*}{$3 \mathrm{rd}$} & \multirow{2}{*}{$\begin{array}{l}\text { light and } \\
\text { information }\end{array}$} & $\begin{array}{l}\text { unmanned intelligent vehicle based on } \\
\text { photoelectric navigation }\end{array}$ & \multirow{2}{*}{$\begin{array}{l}\text { August } \\
10-12,2012\end{array}$} & \multirow{2}{*}{57} & \multirow{2}{*}{ Fujian Normal Univ./Fuzhou } \\
\hline & & $\begin{array}{l}\text { audio source localization and speech } \\
\text { content analysis by laser emission }\end{array}$ & & & \\
\hline \multirow{2}{*}{4 th } & \multirow{2}{*}{$\begin{array}{l}\text { light and } \\
\text { measurement }\end{array}$} & $\begin{array}{l}\text { intelligent mobile measuring vehicle } \\
\text { based on photoelectric navigation }\end{array}$ & \multirow{2}{*}{$\begin{array}{l}\text { August 4-6, } \\
2014\end{array}$} & \multirow{2}{*}{63} & \multirow{2}{*}{$\begin{array}{l}\text { National Univ. of Defense } \\
\text { Technology /Changsha }\end{array}$} \\
\hline & & $\begin{array}{l}\text { non-contact optical measurement of the } \\
\text { volume of objects having complex surface }\end{array}$ & & & \\
\hline \multirow[t]{2}{*}{5 th } & \multirow{2}{*}{$\begin{array}{l}\text { intelligent } \\
\text { light }\end{array}$} & $\begin{array}{l}\text { airdrop rescue unmanned aerial vehicle } \\
\text { based on photoelectric target recognition }\end{array}$ & \multirow{2}{*}{$\begin{array}{l}\text { July } 27-29 \\
2016\end{array}$} & \multirow[t]{2}{*}{82} & \multirow{2}{*}{$\begin{array}{l}\text { Univ. of Electronic Science and } \\
\text { Technology of China /Chengdu }\end{array}$} \\
\hline & & Optimal imaging system with single lens & & & \\
\hline
\end{tabular}


Figure 1 shows the corresponding logo of each NUSOSTC session. There were 16 universities, 41 teams, 121 students and 82 universities, 276 teams, 828 students participating respectively in the first and the fifth NUSOSTC finals. Those final participants were selected via competitions of university, province or district, thus the five NUSOSTCs held during 2008 to 2016 had attracted about 10 thousand students. Provinces and districts involved were across more than half of China and identified on the map of China with a red box in Figure 2.
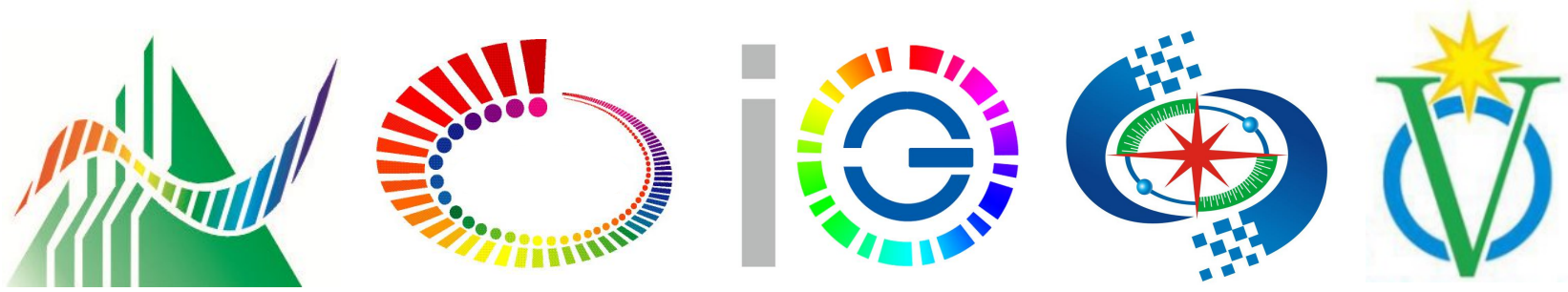

Figure 1. Each session logo of the five NUSOSTCs

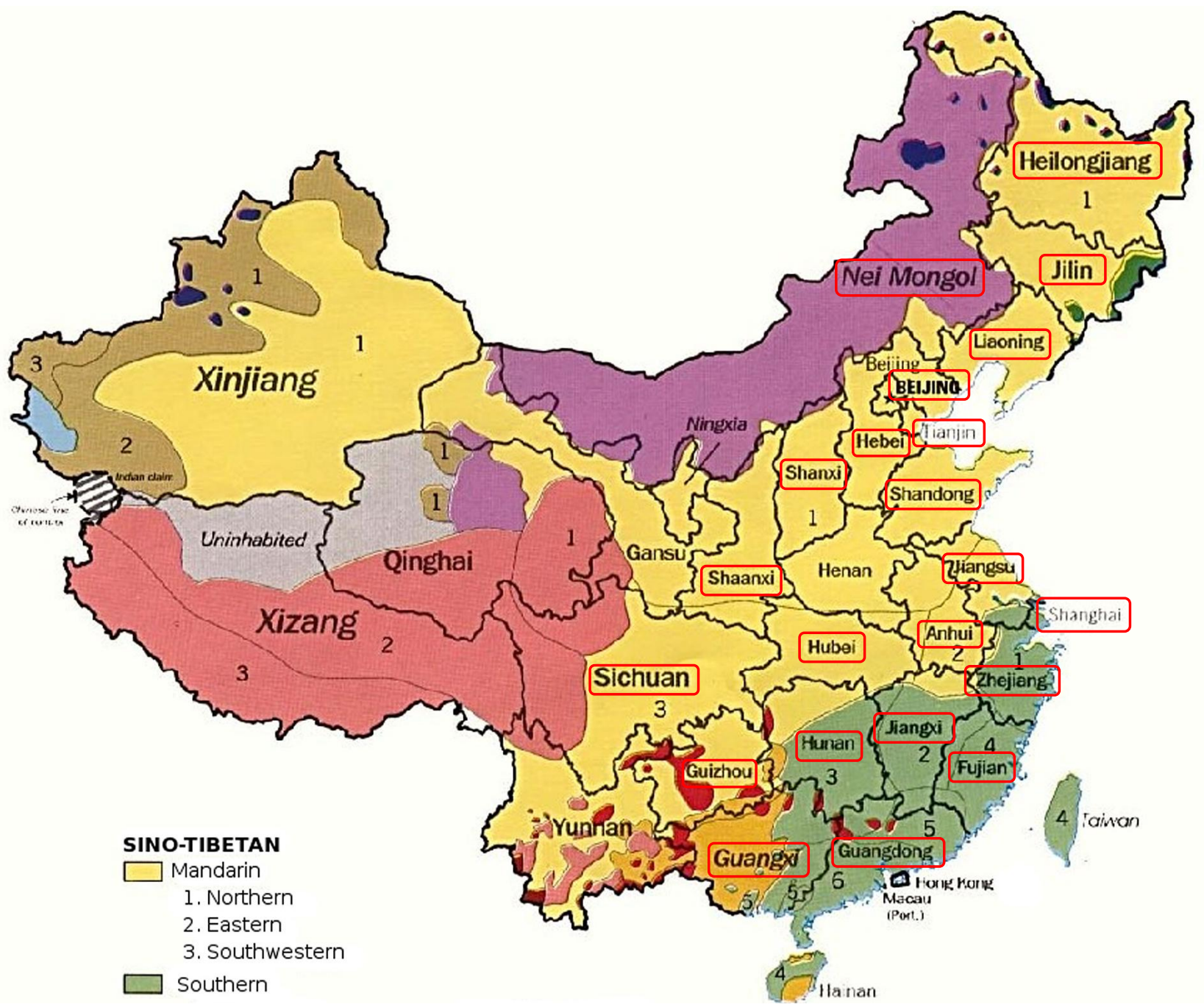

Figure 2. Distribution map of the provinces and districts involved in NUSOSTC 
There were 82 colleges and universities participating in the fifth NUSOSTC final, logos of which are shown in Figure 3.
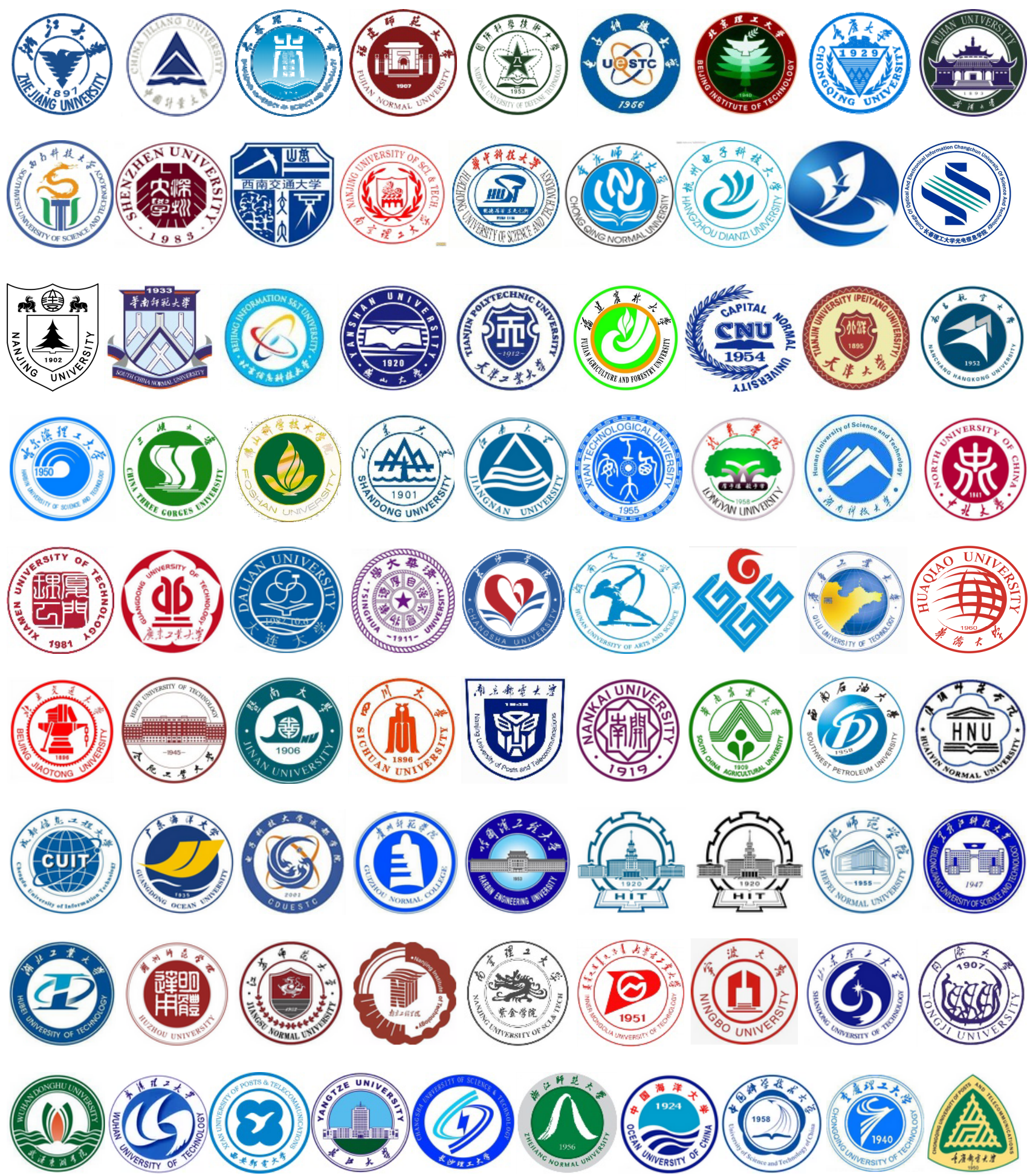

Figure 3. Logos of the 82 colleges and universities participating in the fifth NUSOSTC final 


\section{CONCLUSIONS}

NUSOSTC has made great progress since its establishment in 2008. In terms of the competition strategy, the first is to determine the competition theme around optics \& photonics discipline, to create the competition titles based on the theme, to organize the competition according the titles; the second is to set up a stable service team of experts who are mostly members of the OEDCOS standing committee and of the NESCOP committee; the third is to form a competition mode of holding NUSOSTC every two years and every other year with the National Undergraduate Electronic Design Contest so that senior undergraduates have at least a chance to take part in the above two competitions. In terms of the competition organization, a complete set of processes and programs concerning the selection of NUSOSTC final undertakers, the creation of the competition titles, the raise of competition funds and the implementation of the competition, which ensures the participation, normalization and influence of NUSOSTC. In terms of the competition scale, participating colleges, universities and students are increasing. In terms of the competition sustainable development, NUSOSTC overall organizational structure has been established, including not only the establishment of an independent organization and execution mechanism, but also the set of future strategic goals to hold graded regional elimination matches of NUSOSTC, to introduce long-term cooperation partners, to invite overseas students to participate and to construct a national discipline competition brand. There are reasons to believe that NUSOSTC will be better and better.

\section{ACKNOWLEDGEMENTS}

We would like to give thanks to the members of OEDCOS standing committee and CNTSCEE committee for their supports on NUSOSTC promotion, to the teachers and students from all over the country colleges and universities participating in NUSOSTC, to the excellent organization work of the five NUSOSTC undertakers and co-undertakers, to the State Key Laboratory of Modern Optical Instrumentation for its sponsoring the first and the second NUSOSTC, to the OMRON automation (China) Co., Ltd. for it continuous sponsoring the third, the fourth and the fifth NUSOSTC, and all of the other companies sponsoring the five NUSOSTCs. Construction of the NUSOSTC is also a part of "the second batch of '12th Five-Year' Zhejiang provincial experimental teaching demonstration center key construction project" approved in 2015 by the Department of Education of Zhejiang Province. 